\title{
A note on commuting times and city size: Testing variances as well as means
}

\author{
Qian An ${ }^{\text {a }}$ \\ University of Southern California
}

\author{
Peter Gordon ${ }^{b}$ \\ University of Southern California
}

\author{
James E. Moore II c \\ University of Southern California
}

\begin{abstract}
Relatively little attention has been paid to the relationship between commute time variances and city size. In this paper, we utilize 2009 Nationwide Highway Travel Survey data and test the relationship between area commute-time means as well as variances in metropolitan-area size. We include tests for metropolitan areas as a whole and for residents from urban, suburban, second city, and town-and-county areas. The regression analysis shows that all estimated slopes are statistically significant but not much greater than zero. Commute time means and variances are highly correlated. These relationships are also invariant with respect to the place of residence. An extensive collection of literature provides evidence for the co-location of workers and jobs hypothesis: average commute times do not rise appreciably as metropolitan population increases. We conclude that these results are additional, although indirect, evidence for the co-location hypothesis.
\end{abstract}

\section{Introduction}

"Sprawl" is a vague and pejorative term. The critics of sprawl refer to outward metropolitan growth, we use the term the same way. Anas (2012) provides a succinct and timely introduction to the perennial debate concerning the costs of sprawl. Bruegmann (2005) reminds us that sprawl is long-standing and almost universal. As cities grow, they expand outward and the costs of the resulting sprawl are thought to dominate and also limit further growth. Increased transportation costs are often cited as a major component of urban growth costs. A simple rendering of the story defines the original static model of optimal urban size, in which the costs of city size increase at an increasing rate, but the benefits increase at a decreasing rate. The two curves must eventually cross, defining the optimal urban scale (Figure 1). Putting aside the discussion of how such curves might shift in a dynamic setting, it is also of interest to question their hypothesized shape. See Richardson (1973) for the full critique.

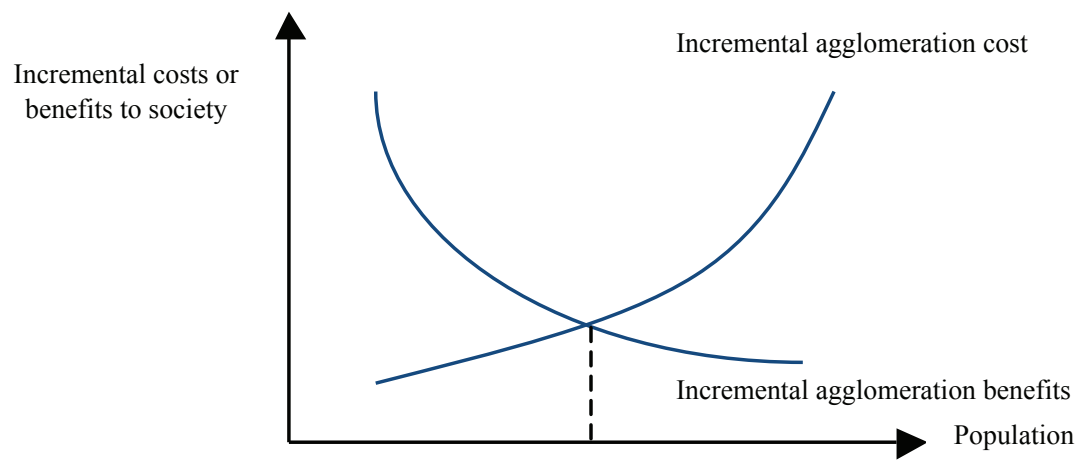

Figure 1: Incremental costs and benefits of agglomeration.

\footnotetext{
${ }^{\mathrm{a}}$ qan@usc.edu

b pgordon@usc.edu

c jmoore@usc.edu
}

Copyright 2014 Qian An, Peter Gordon, and James E. Moore II.

Licensed under the Creative Commons Attribution - NonCommercial License 3.0. 


\section{The role of sprawl}

The market failures associated with highway traffic congestion are well known. When access is unpriced, congestion is the default rationing mechanism. Beyond this, the extra commuting costs associated with urban growth and expansion have been studied extensively by investigators interested in the costs of sprawl. However, the association between sprawl and commuting costs has also been challenged. Employers as well as populations suburbanize almost everywhere. This recognition suggests that it is likely that employers and employees each have incentives to co-locate to the suburbs in ways that reduce the costs of interacting with each other. Each locator trades off a large number of attractors and repellers associated with a large number of possible locations, but firms' access to labor is separately important for both employees and employers. With enough such co-location, urban sprawl can be thought of as an accommodation to urban growth, scale, and spread. From this point of view, it is a solution instead of the problem. Much of this literature is cited and discussed in Gordon and Richardson (2012).

We refer to "cities," but emphasize the entire metropolitan area. We now observe larger metropolitan regions and even mega-regions worldwide. Growing cities are strong evidence of the net advantages they provide. Lee's work (2011) provides evidence for the benign co-location view of size. Using U.S. Census journey-to-work data, he analyzes commuting trip times for a cross-section of 79 large U.S. metro areas. He classifies workers by their place of work within each area:

(i) The central business district (accounting for 7 percent of workers in the 14 metro areas above 5 million in population in 2000),

(ii) The various subcenters (accounting for 15 percent), or

(iii) "Dispersed" (accounting for 78 percent; census tracts with employment densities too low to qualify as subcenters).

Two of Lee's findings are:

(i) As metro-area populations get larger, average trip times increase, but the slope associated with this increase is quite shallow; and

(ii) The slope is even shallower if only subcenter workers are considered, and shallowest if only dispersed workers are considered.

Defining subcenters can be subjective, but Lee utilizes two methods to identify centers and sub-centers. His findings are similar in both cases. Lee's results for the drive-alone commute mode appear in Figure 2.

Others find similar results. Anas (2012) reports that "The data on the largest U.S. MSAs show that commute times increase only slightly with city size: the elasticity of the average commute time with respect to the number of workers was about 0.1 in 1990 and 2000" (p. 146).

\section{Travel time variance}

The empirical relationship between mean travel times and city size provides some support for the accommodation view. What do we expect when studying travel time variances and their relationship to city size? Estimated means are less sensitive to outlier values than are estimated variances. This suggests that a stronger test of the accommodation hypothesis involves variances.

We use data from self-reported trip diaries from the 2009 Nationwide Highway Travel Survey (http://nhts.ornl.gove/). NHTS describes the place of residence of interviewees along an urban continuum from "most central" to most "suburban-exurban." NHTS populations and metropolitan-area designations are slightly smaller than those conventionally used, but we adopt the NHTS categories of 

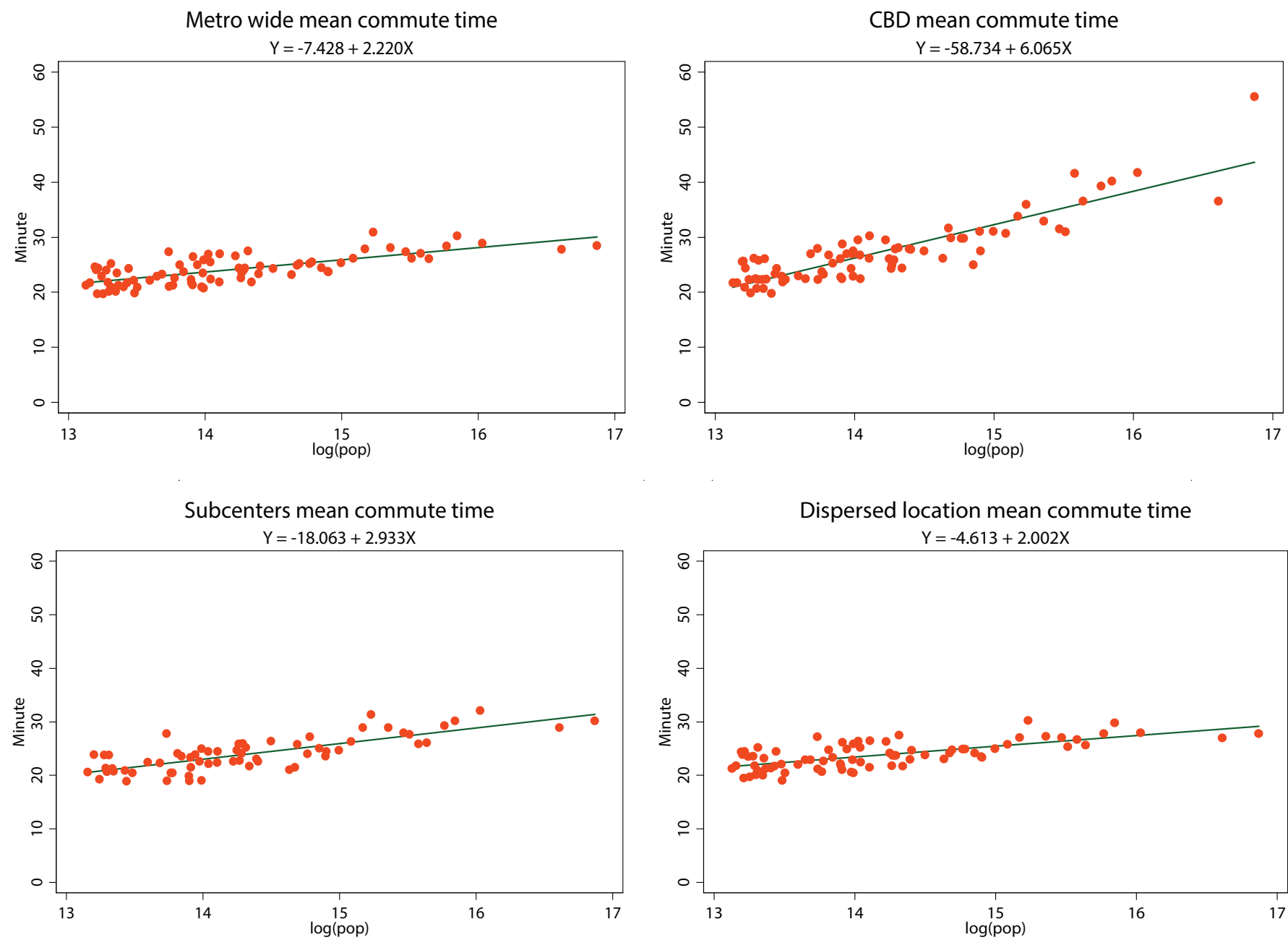

Figure 2: Mean commute time by workplace location type versus metro population size (Lee 2011).

"urban," "suburban," "second city," and "town and country" and examine data for these four categories as well as for each metropolitan area as a whole. These are, perhaps, not ideal categories, but they capture useful qualitative differences.

We estimate relationships between mean one-way work-trip travel time (in minutes) and city size. We make the same estimation for the relationship between variance of travel time and city size. Like Lee, we restricted the analysis to data for solo, privately operated vehicles only. There are 10 relationships of interest. There are 47 observations, one for each of the largest U.S. metropolitan areas, for each case except the "urban" category. Figure 3 shows the estimated relationship for metropolitan areas as a whole. Table 1 summarizes the estimated elasticities for the $\ln ($ mean) and $\ln$ (variance) vs. $\ln$ (population) estimations. The comparisons demonstrate small elasticities in either set of regressions and show no more than minor differences across geographic place of residence categories.

These results reveal the following:

(i) All of the estimated elasticities regarding mean commuting times are small, although statistically different from zero. All are close to the 0.10 elasticity reported by Anas.

(ii) These estimated elasticities are almost invariant relative to (NHTS) place of residence.

(iii) The elasticities with respect to mean travel time against population are slightly smaller than the 
elasticities for the plots of variances vs. population.

(iv) Mega-cities Los Angeles and New York appear to have lower means and variances compared to the predicted values.

Regressions with regard to variances show similar results. For metropolitan areas as a whole, urban, suburban, second city, and town and country, the correlations between work-trip means and variances are $0.824,0.665,0.618,0.679$, and 0.788 , respectively. Further, the small slopes for variance estimates indicate that as cities expand, the variation only increases slightly.

\section{$\ln ($ mean $) \sim \ln ($ population $)$}

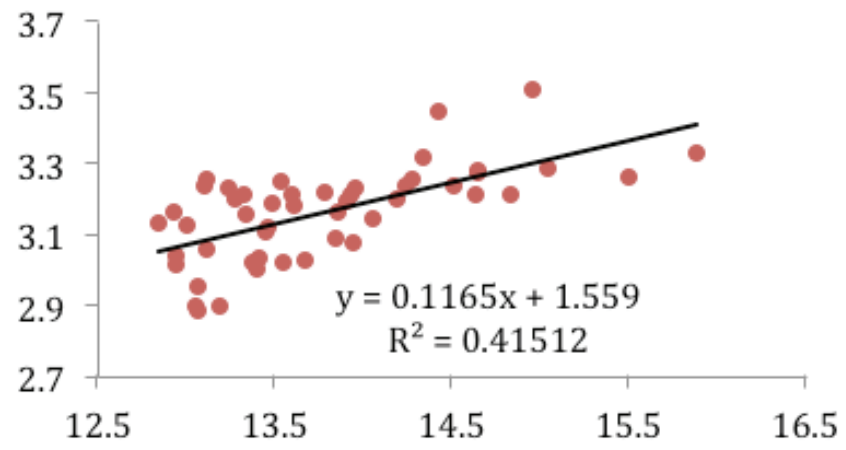

$\ln ($ variance $) \sim \ln ($ population $)$

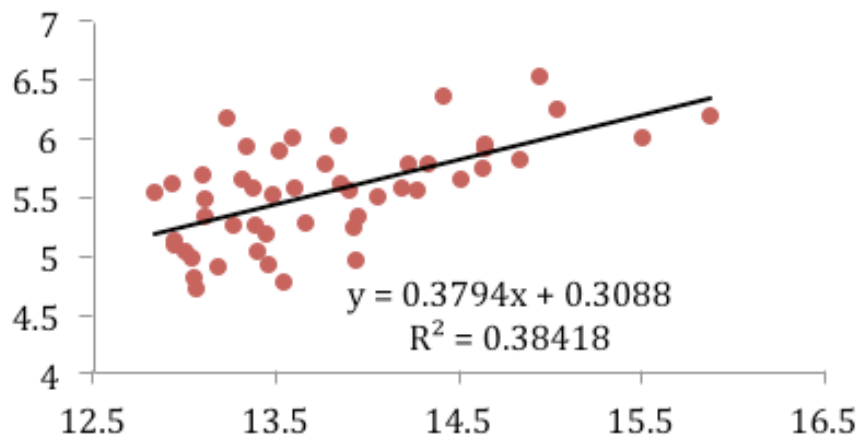

Figure 3: Metropolitan (pooled).

The close association between average work-trip times and variances and the increases in both Table 1: Summary of estimated elasticities.

\begin{tabular}{|l|l|l|l|l|}
\hline \multicolumn{5}{|c|}{ Dependent Variable } \\
\hline Area & Means & Variances & $\begin{array}{l}\text { Means with Census Divi- } \\
\text { sion Controls }\end{array}$ & $\begin{array}{l}\text { Variances with Census } \\
\text { Division Controls }\end{array}$ \\
\hline Metro & 0.1165 & 0.3794 & 0.1407 & 0.4149 \\
Urban & 0.1457 & 0.4198 & 0.1355 & 0.3616 \\
Suburban & 0.1425 & 0.5329 & 0.1518 & 0.5210 \\
Second City & 0.1533 & 0.5384 & 0.1927 & 0.5833 \\
Town \& Country & 0.1122 & 0.3978 & 0.1271 & 0.4159 \\
\hline
\end{tabular}

work-trip times and variances with population suggests a possible decrease in travel-time reliability in the largest cities, at least for auto users. However, even if travel-time reliability is assumed fixed, larger cities include more outliers, both with respect to opportunities and behaviors, and a larger metro system will show a wider range of travel behaviors.

Would choice-of-mode differences across cities explain our results? Transit may be part of the story, but a larger city does not imply a larger transit share. In our sample of 47 metropolitan areas, mode choice proportions are very similar, with the exception of New York. The proportion of solo private auto commuters is on average 78 percent. Without New York, it is 79 percent. The proportion of private auto commuters (not just solo drivers) is on average 92 percent. Without New York, it is 94 percent, yet Los Angeles and New York are similar outliers in this analysis. These two cities are below the estimated regression line, especially when using direct, not-scaled population as the independent variable. Thus 
the size effect is most muted for the largest places. Institutional efforts to amplify the role of transit might provide cities with a mechanism for accommodating scale, but co-location strategies are always available and require no central authority to pursue.

Regressions using density as the independent variable, and regressions using population and density as independent variables, were also performed. When density alone is used as the independent variable, only half of the coefficient estimates in the various regressions are statistically significant. When both density and population are used as independent variables, none of the coefficients for density are statistically significant, most likely the result of collinearity. For regressions using mean commute time as the dependent variance and $\ln$ (population) as the independent variable, all coefficients for mean commute time are around 3.0, which is quite consistent with Lee's (2011) work summarized in Figure 2.

\section{Conclusions}

Mean travel times do not rise appreciably with metro-area population or location, but neither do the variances of travel times, and these variances are much more sensitive to outlier values. Sprawl, at least as measured by commuting costs, appears to be less of a market failure amplifying efficiency losses in larger cities than it is a co-location mechanism for mitigating road and highway network costs and externalities.

A second set of 10 regressions added census divisions as indicator variables to the models summarized in Table 1, providing a rough proxy for city development vintage. Even with this set of controls in place, the estimation results provide no evidence to modify our conclusions with respect to area population explaining either the variation of travel time means or travel time variances.

There are always possibly competing explanations. Another possible source of commute variation might be greater industrial specialization among the large cities. However, it is well known that among the large cities, levels of industrial specialization are quite low. See, for example, Kemeny and Storper (2012) and Hollar (2006).

Still, there have been many doomsayers through history, and most have been wrong. Matt Ridley in The Rational Optimist (2010) documents much of this, and we put concerns about the costs of sprawl in this category. Julian Simon (1995) explains why "impending doomsday" is always impeding. He also lays out the case for why forecasts of future doom are likely to be wrong.

Co-location strategies are most often explained in terms of the objectives of employers and employees, a perspective that overlooks the work trip's ever-diminishing share of urban travel. The next logical step in this analysis is to conduct similar tests for non-work travel. The NHTS data made this further study possible.

\section{References}

Anas, A. 2012. Discovering the efficiency of urban sprawl. In The Oxford Handbook of Urban Economics and Planning, edited by N. Brooks, K. Donaghy, and G. J. Knaap. New York: Oxford University Press. http://dx.doi.org/10.1093/oxfordhb/9780195380620.013.0007.

Bruegmann, R. 2005. Spawl: A Compact History. Chicago: University of Chicago Press.

Gordon, P., and H. W. Richardson. 2012. Urban structure and urban growth. In The Oxford Handbook of Urban Economics and Planning, edited by N. Brooks, K. Donaghy, and G. J. Knaap. New York: Oxford University Press. 
Hollar, M. 2006. Industrial diversity and agglomeration economies. Working Paper \#REP 06-03, U.S. Department of Housing and Urban Development.

Kemeny, T., and M. Storper. 2012. Specialization and regional economic development. No. 0121, Spatial Economics Research Centre, LSE.

Lee, B., and P. Gordon. 2011. Urban structure: its role in urban growth, net new business formation and industrial churn. Région et Dévelopment 33: 137-159.

Richardson, H. W. 1973. The Economics of Urban Size. Lexington, MA: Saxon House.

Ridley, M. 2010. The Rational Optimist: How Prosperity Evolves. New York: Harper-Collins.

Santos, A., M. Nancy, H. Y. Nakamoto, D. Gray, and S. Liss. 2009. Summary of Travel Trend: 2009 National Household Travel Survey. FHWA-PL-11-022, Federal Highway Administration.

Simon, J. L. 1995. The State of Humanity. Oxford, UK, and Cambridge USA: Blackwell. 